\title{
Real-time real-world analysis of seasonal influenza vaccine effectiveness: method development and assessment of a population-based cohort in Stockholm County, Sweden, seasons 2011/12 to 2014/15
}

\author{
A Leval ${ }^{1234}$, MP Hergens ${ }^{124}$, K Persson ${ }^{1}$, Å Örtqvist ${ }^{12}$ \\ 1. Department of Communicable Disease Control and Prevention for Stockholm County, Stockholm, Sweden \\ 2. Infectious Disease Unit, Karolinska Institutet, Department of Medicine Solna, Solna, Sweden \\ 3. Janssen-Cilag, Solna, Sweden \\ 4. These authors contributed equally to this manuscript
}

Correspondence: Åke Örtqvist (ake.ortqvist@sll.se)

Citation style for this article:

Leval A, Hergens MP, Persson K, Örtqvist Å. Real-time real-world analysis of seasonal influenza vaccine effectiveness: method development and assessment of a population-based cohort in Stockholm County, Sweden, seasons 2011/12 to 2014/15. Euro Surveill. 2016;21(43):pii=30381. D0I: http://dx.doi.org/10.2807/15607917.ES.2016.21.43.30381

Article submitted on 20 May 2016 / accepted on 12 September 2016 / published on 27 October 2016

Real-world estimates of seasonal influenza vaccine effectiveness (VE) are important for early detection of vaccine failure. We developed a method for evaluating real-time in-season vaccine effectiveness (IVE) and overall seasonal VE. In a retrospective, register-based, cohort study including all two million individuals in Stockholm County, Sweden, during the influenza seasons from 2011/12 to $2014 / 15$, vaccination status was obtained from Stockholm's vaccine register. Main outcomes were hospitalisation or primary care visits for influenza (International Classification of Disease (ICD)10 codes J09-J11). VE was assessed using Cox multivariate stratified and non-stratified analyses adjusting for age, sex, socioeconomic status, comorbidities and previous influenza vaccinations. Stratified analyses showed moderate VE in prevention of influenza hospitalisations among chronically ill adults $\geq 65$ years in two of four seasons, and lower but still significant VE in one season; $53 \%$ ( $95 \%$ confidence interval $(\mathrm{CI})$ : $33-67)$ in 2012/13, $55 \%$ (95\% Cl: 25-73) in 2013/14 and $18 \%$ (95\% Cl: 3-31) in 2014/15. In conclusion, seasonal influenza vaccination was associated with substantial reductions in influenza-specific hospitalisation, particularly in adults $\geq 65$ years with underlying chronic conditions. With the use of population-based patient register data on influenza-specific outcomes it will be possible to obtain real-time estimates of seasonal influenza VE.

\section{Introduction}

Annual vaccination against circulating influenza viruses remains the best strategy for preventing illness from influenza. A clear challenge, however, is that vaccine effectiveness (VE) varies from year to year [1]. These variations may be due to differences in antigenic match between the vaccine and the circulating strain, the immune status of those who are being vaccinated, or the time interval between vaccination and influenza outbreak.

Influenza outcome specificity is an important factor affecting VE estimates, since outcomes with low specificity will either underestimate or overestimate influenza VE $[2,3]$. Seasonal influenza VE uncertainty is an important reason for obtaining estimates for inseason vaccine effectiveness (IVE) as early as possible $[2,4,5]$. Such estimates may help guide the outbreak response, especially if there are signs of an antigenic mismatch that might require complementary public health measures.

There are controversies concerning the overall influenza VE, especially in elderly people, in most studies defined as adults $\geq 65$ years of age $[6,7]$. Real-world evidence of vaccine effectiveness is therefore imperative for future influenza vaccine development and programme evaluation. The seasonal influenza vaccination programme in Stockholm offers vaccination at no outof-pocket cost to individuals aged 65 years and older, pregnant women, and people of any age with certain underlying risk factors (chronic diseases of the heart, lungs, kidneys or liver, diabetes mellitus, neurological disease affecting the patient's lung function, obesity with a body mass index of $>40$, and immunosuppression caused by a disease or treatment). The actual benefit to these targeted groups is largely unknown and the aim of this study was therefore to develop methods for evaluating IVE and the overall seasonal vaccine effectiveness (VE) in all persons, irrespective of underlying risk factors, with medically attended influenza 


\section{FIGURE}

Number and incidence of laboratory-confirmed influenza cases, and number of patients hospitalised with influenza diagnosis in Stockholm County, influenza seasons 2011/12-2014/15

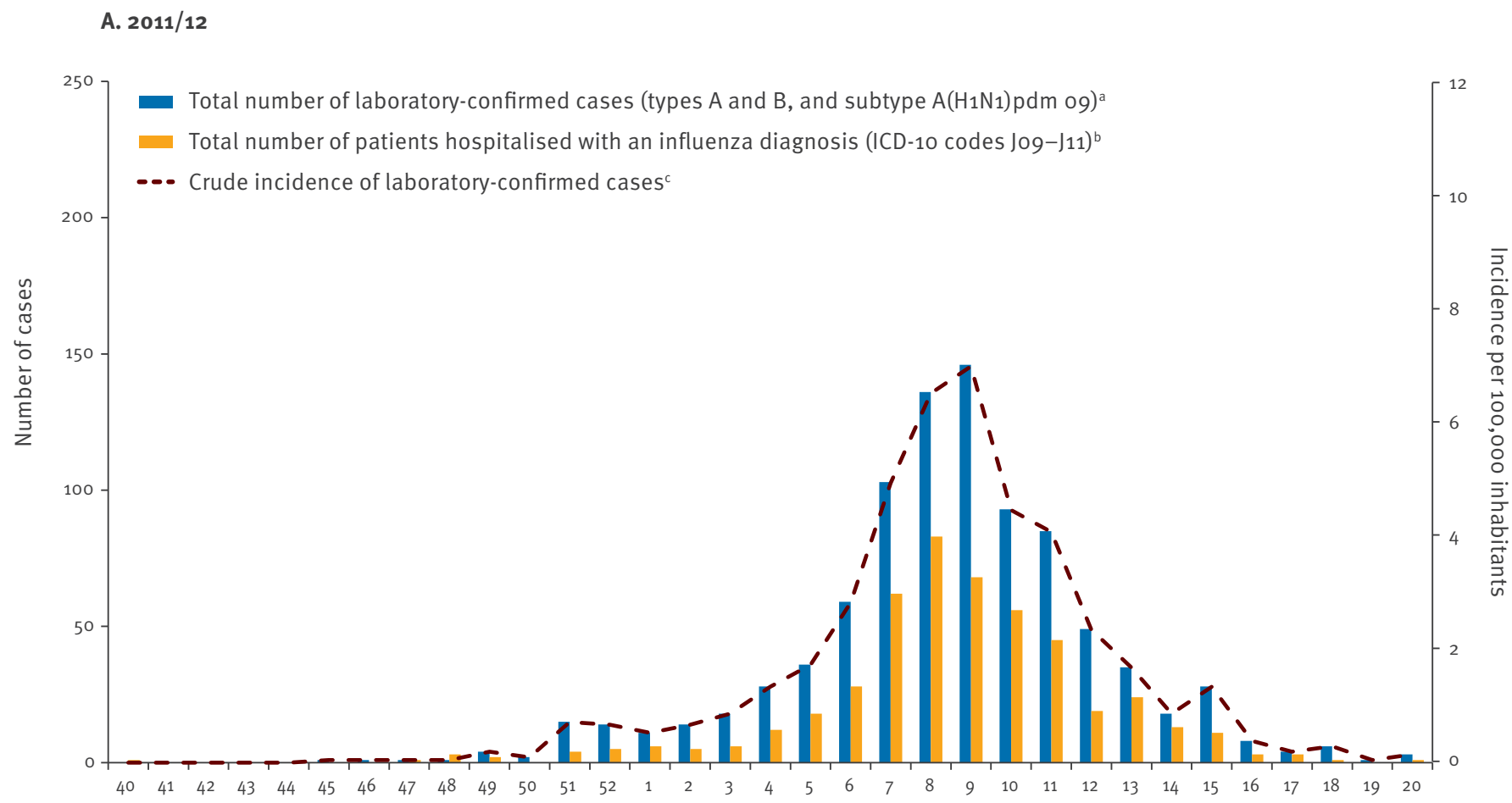

Week

\section{B. 2012/13}

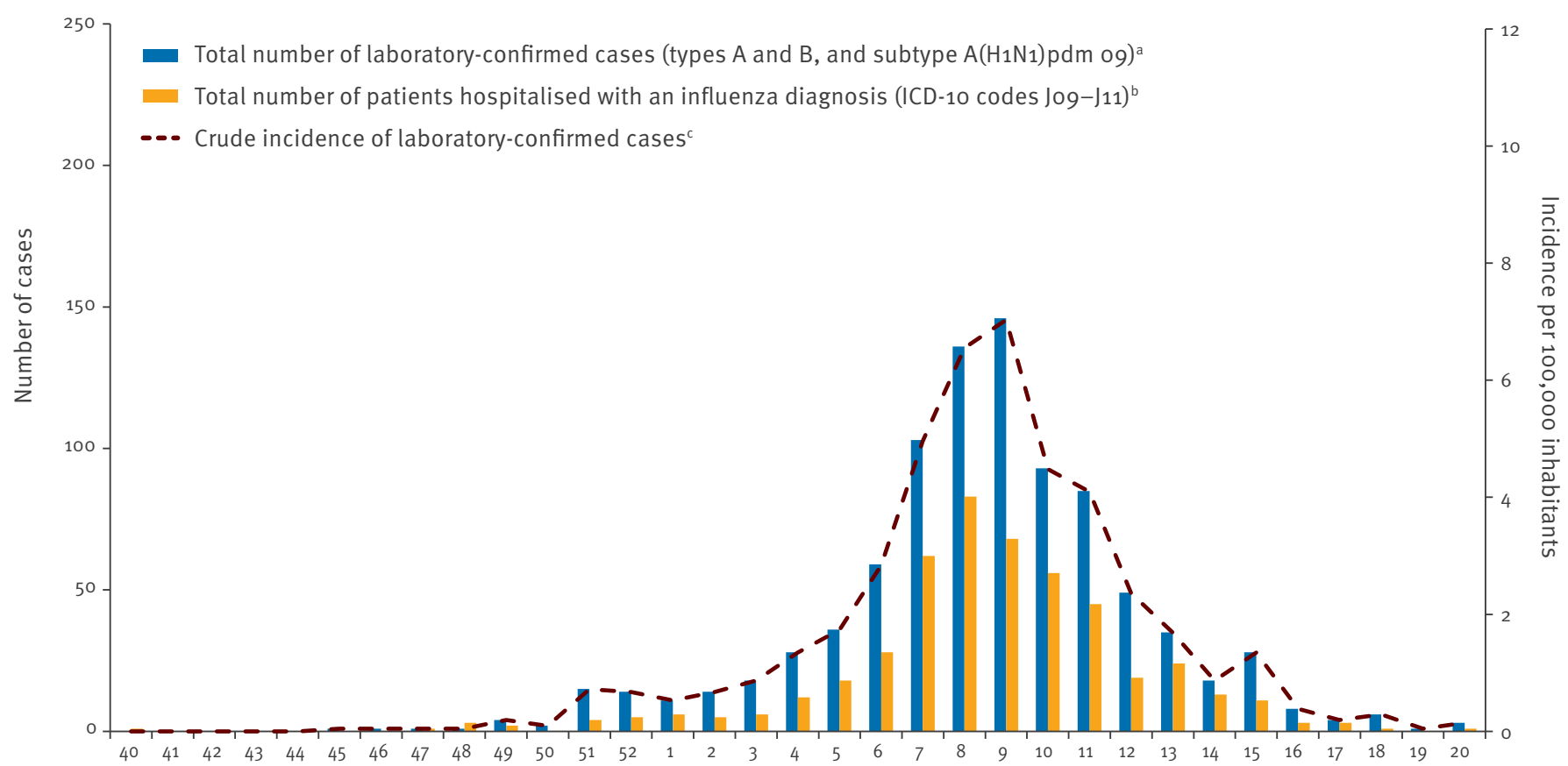

Week

ICD: International Classification of Diseases.

Unadjusted incidence calculated by number of laboratory-confirmed cases per 100,000 inhabitants. Numbers reported by calendar week each season.

No data were available on number of laboratory-confirmed hospitalised influenza cases due to anonymous data in the central database for healthcare utilisation, making linkage impossible.

a Data obtained from the Public Health Agency of Sweden

${ }^{b}$ Data collected in Stockholm County's central database for healthcare utilisation using ICD-10 codes J09-J11

${ }^{c}$ (Number of laboratory-confirmed cases/number of inhabitants in Stockholm during season) × 100,000. 


\section{FIGURE}

Number and incidence of laboratory-confirmed influenza cases, and number of patients hospitalised with influenza diagnosis in Stockholm County, influenza seasons 2011/12-2014/15

\section{2013/14}

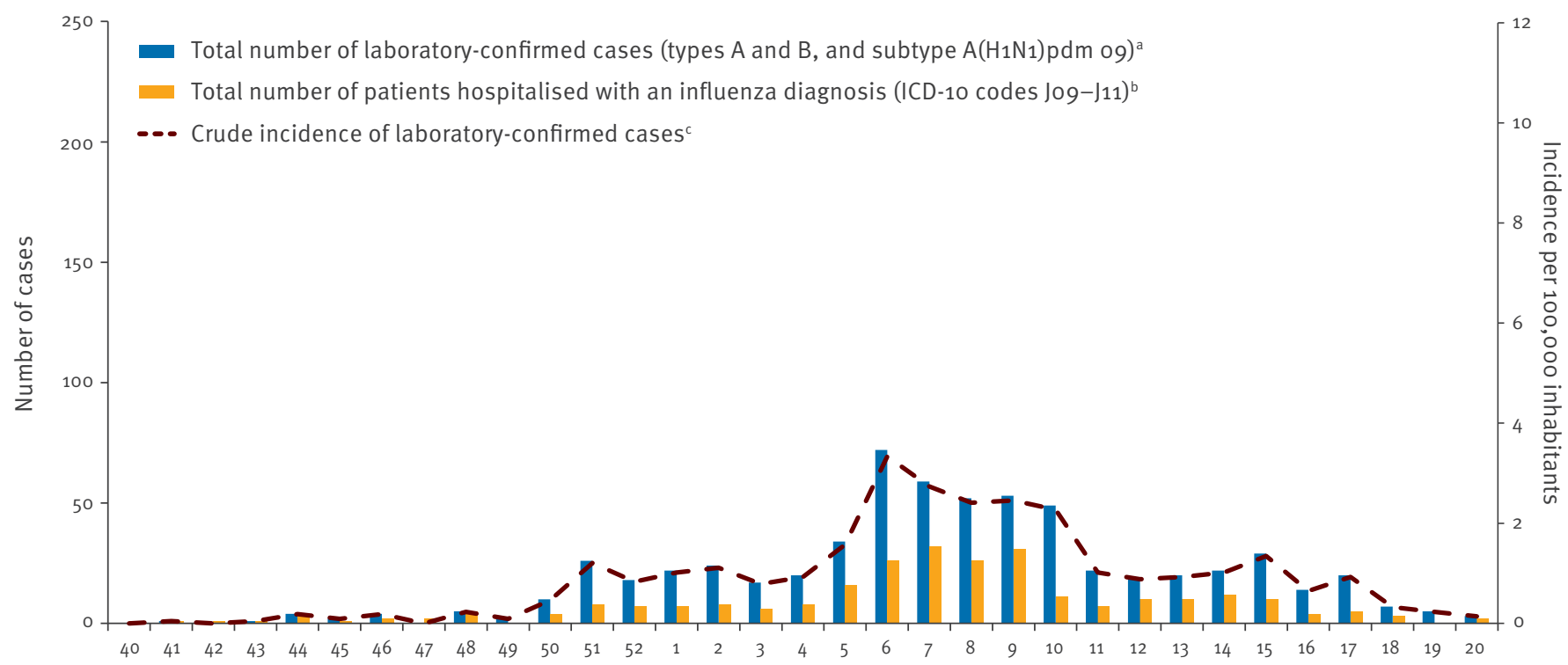

Week

\section{2014/15}

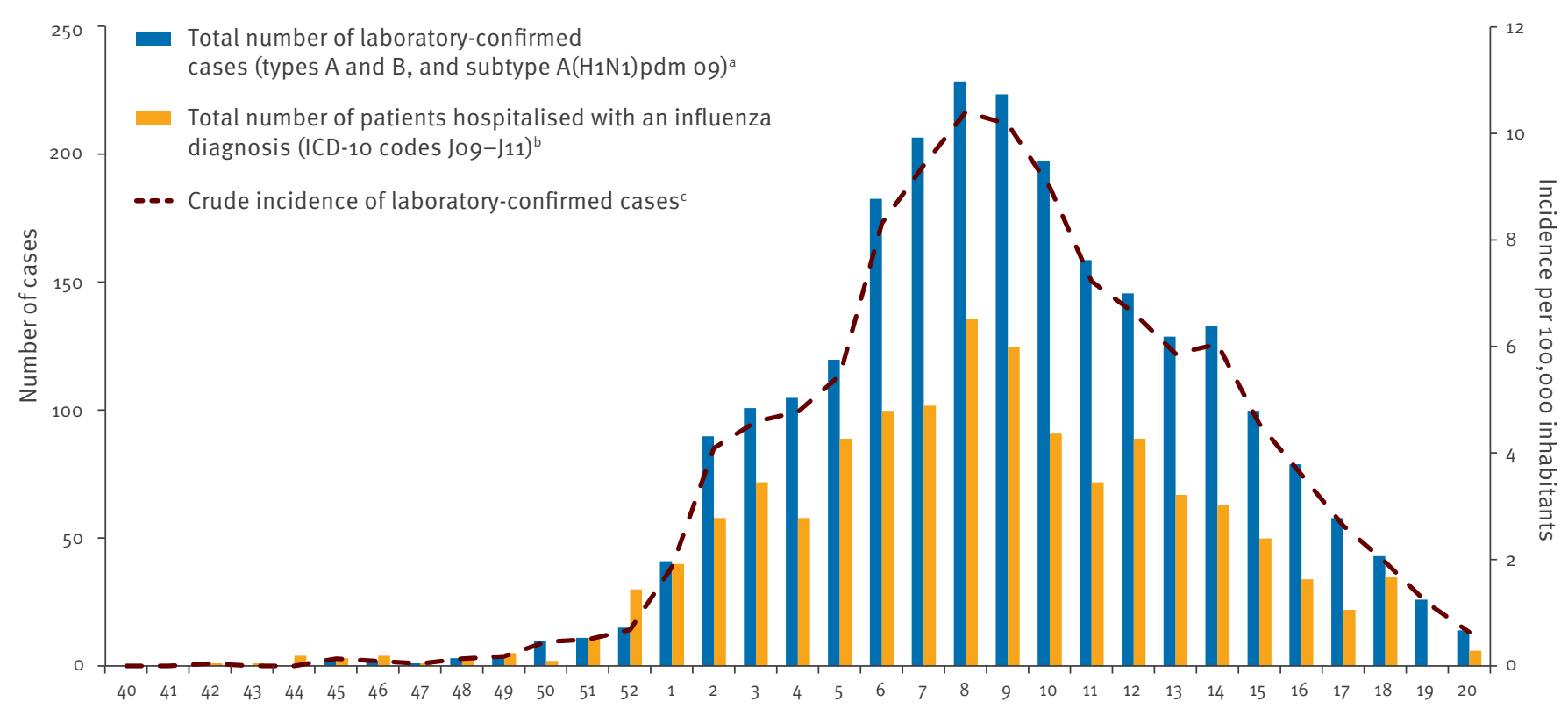

Week

ICD: International Classification of Diseases.

Unadjusted incidence calculated by number of laboratory-confirmed cases per 100,000 inhabitants. Numbers reported by calendar week each season.

No data were available on number of laboratory-confirmed hospitalised influenza cases due to anonymous data in the central database for healthcare utilisation, making linkage impossible.

a Data obtained from the Public Health Agency of Sweden

b Data collected in Stockholm County's central database for healthcare utilisation using ICD-10 codes J09-J11

c (Number of laboratory-confirmed cases/number of inhabitants in Stockholm during season) × 100,000. 
TABLE 1A

Baseline characteristics of the cohorts in influenza analysis, Stockholm County, influenza seasons 2011/12 and 2012/13

\begin{tabular}{|c|c|c|c|c|c|c|}
\hline \multirow{3}{*}{ Characteristic } & \multicolumn{3}{|c|}{ Influenza season 2011/12 } & \multicolumn{3}{|c|}{ Influenza season $2012 / 13$} \\
\hline & Total & Vaccinated $^{\mathrm{a}}$ & Unvaccinated & Total & Vaccinated $^{\mathrm{a}}$ & Unvaccinated \\
\hline & $n$ & n (\%) & n (\%) & n (\%) & n (\%) & $\mathrm{n}(\%)$ \\
\hline Cohort total & $2,089,047$ & $205,415(9.8)$ & $1,883,612(90.2)$ & $2,121,469$ & $185,646(8.8)$ & $1935,823(91.2)$ \\
\hline \multicolumn{7}{|l|}{ Sex } \\
\hline Male & $1,034,494$ & $87,659(8.5)$ & $946,835(91.5)$ & $1,051,818(49.6)$ & $79,920(7.6)$ & $971,898(92.4)$ \\
\hline Female & $1,054,553$ & $117,756(11.2)$ & $936,797(88.8)$ & $1,069,651(50.4)$ & $105,726(9.9)$ & $963,925(90.1)$ \\
\hline \multicolumn{7}{|l|}{ Age group in years } \\
\hline$<10$ & 270 & $388(0.1)$ & 270,435 (99.9) & $276,358(13.0)$ & $273(0.1)$ & $276,085(99.9)$ \\
\hline $10-19$ & 232 & $540(0.2)$ & 231,971 (99.8) & $231,869(10.9)$ & $388(0.2)$ & $231,481(99.8)$ \\
\hline $20-29$ & 283,977 & $1,373(0.5)$ & $282,604(99.5)$ & 291,993 (13.8) & $1,014(0.4)$ & $290,979(99.6)$ \\
\hline $30-39$ & 320,932 & $3,219(1.0)$ & $317,713(99.0)$ & $322,867(15.2)$ & $2,437(0.8)$ & $320,430(99.2)$ \\
\hline $40-49$ & 307,966 & $4,457(1.4)$ & $303,509(98.6)$ & $313,605(14.8)$ & 3,499 (1.1) & 310,106 (98.9) \\
\hline $50-59$ & 241,944 & $8,340(3.4)$ & $233,604(96.6)$ & $246,848(11.6)$ & $6,916(2.8)$ & $239,932(97.2)$ \\
\hline $60-69$ & 223,956 & $60,580(27.0)$ & $163,376(73.0)$ & $224,713(10.6)$ & $52,719(23.5)$ & $171,994(76.5)$ \\
\hline $70-79$ & 121,415 & $73,510(60.5)$ & $47,905(39.5)$ & $127,570(6.0)$ & $70,014(54.9)$ & $57,556(45.1)$ \\
\hline$\geq 80$ & 85,523 & $53,008(62.0)$ & $32,515(38.0)$ & $85,646(4.0)$ & $48,386(56.5)$ & $37,260(43.5)$ \\
\hline \multicolumn{7}{|c|}{ Mosaic income/education categories } \\
\hline $\begin{array}{l}\text { Highest income and } \\
\text { education }\end{array}$ & 945,893 & $94,506(10.0)$ & $851,387(90.0)$ & 971,845 & $85,992(8.8)$ & $885,853(91.2)$ \\
\hline $\begin{array}{l}\text { Middle income and } \\
\text { education }\end{array}$ & 360,980 & $36,871(10.2)$ & $324,109(89.8)$ & 372,925 & $33,095(8.9)$ & $339,830(91.1)$ \\
\hline $\begin{array}{l}\text { Lowest income and } \\
\text { education }\end{array}$ & 744,905 & $73,067(9.8)$ & $671,838(90.2)$ & 761,746 & $66,032(8.7)$ & $695,714(91.3)$ \\
\hline Missing & 37,269 & $1,450(3.9)$ & $35,819(96.1)$ & 14,653 & $536(3.7)$ & $14,117(96.3)$ \\
\hline \multicolumn{7}{|l|}{ Comorbidity } \\
\hline Yes & 586,470 & $148,196(25 \cdot 3)$ & $438,274(74.7)$ & $613,183(28.9)$ & $138,020(22.5)$ & $475,163(77.5)$ \\
\hline No & $1,502,577$ & $57,219(3.8)$ & $1,445,358(96.2)$ & $1,508,286(71.1)$ & $47,626(3.2)$ & $1,460,660(96.8)$ \\
\hline \multicolumn{7}{|c|}{ Previous seasonal vaccination ${ }^{b}$} \\
\hline Yes & 203,736 & $162,379(79.7)$ & $41,357(20.3)$ & $198,361(9.4)$ & $151,359(76.3)$ & $47,002(23.7)$ \\
\hline No & $1,885,311$ & $43,036(2.3)$ & $1,842,275(97.7)$ & $1,923,108(90.7)$ & $34,287(1.8)$ & $1,888,821(98.2)$ \\
\hline \multicolumn{7}{|c|}{ Pneumococcal vaccination ${ }^{c}$} \\
\hline Yes & 33,374 & $28,232(84.6)$ & $5,142(15.4)$ & $39,502(1.9)$ & $30,891(78.2)$ & $8,611(21.8)$ \\
\hline No & $2,055,673$ & $177,183(8.6)$ & $1,878,490(91.4)$ & $2,081,967(98.1)$ & $154,755(7.4)$ & $1,927,212(92.6)$ \\
\hline \multicolumn{7}{|c|}{ Pandemrix vaccination $^{d}$} \\
\hline Yes & $1,064,132$ & $163,246(15.3)$ & $861,669(84.7)$ & $1,007,546(47.5)$ & $148,338(14.7)$ & $859,208(85.3)$ \\
\hline No & $1,024,915$ & $42,169(4.1)$ & $1,021,963(95.9)$ & $1113923(52.5)$ & $37,308(3.4)$ & $1,076,615(96.6)$ \\
\hline
\end{tabular}

Influenza season defined as 1 October to 31 May in the following year.

${ }^{a}$ During the $2011 / 12$ influenza season, $99.5 \%$ of seasonal influenza vaccinations were carried out using Vaxigrip. During $2012 / 13$, $99.4 \%$ of seasonal influenza vaccinations were carried out using Fluarix.

${ }^{b}$ Vaccinated against seasonal influenza during the previous season.

c Vaccinated against Streptococcus pneumoniae during time period from 2009 to the season under investigation.

${ }^{d}$ Vaccinated against influenza $\mathrm{A}\left(\mathrm{H}_{1} \mathrm{~N}_{1}\right)$ pdmog during the 2009 pandemic.

and pneumonia hospitalisations and primary care cases in Stockholm County, Sweden.

\section{Methods}

\section{Study population and period}

This study was based on four annual closed cohorts each comprising all individuals registered in Stockholm at the start of each season. The influenza season was defined as starting on 1 October and ending on 31 May the following year.

\section{Data sources}

Data were collected using Stockholm County's central database for healthcare utilisation, consultations and diagnoses, VAL. VAL has comprehensive inpatient, hospital outpatient, and primary care data and is used by the County Council to update the national patient register (PR) [8]. Multiple register linkages are possible due to unique personal identification numbers (PIN). Age and sex were retrieved from the primary care listing register in VAL. Immigration and death dates were not available in VAL, necessitating the design of a 
TABLE 1B

Baseline characteristics of cohorts, Stockholm County, influenza seasons 2013/14 and 2014/15

\begin{tabular}{|c|c|c|c|c|c|c|}
\hline \multirow{3}{*}{ Characteristic } & \multicolumn{3}{|c|}{ Influenza season $2013 / 14$} & \multicolumn{3}{|c|}{ Influenza season $2014 / 15$} \\
\hline & Total & Vaccinated $^{a}$ & Unvaccinated & Total & Vaccinated $^{\mathrm{a}}$ & Unvaccinated \\
\hline & $n$ & $\mathrm{n}(\%)$ & $\mathrm{n}(\%)$ & $\mathrm{n}(\%)$ & n (\%) & n (\%) \\
\hline Cohort total & $2,171,207$ & $199,707(9.2)$ & $1,971,500(90.8)$ & $2,207,172$ & $205,709(9.3)$ & $2,001,463(90.7)$ \\
\hline \multicolumn{7}{|l|}{ Sex } \\
\hline Male & $1,077,657$ & $84,692(7.9)$ & $992,965(92.1)$ & $1,096,957(49.7)$ & $88,091(8.0)$ & $1,008,866(92.0)$ \\
\hline Female & $1,093,550$ & $115,015(10.5)$ & $978,535(89.5)$ & $1,110,215(50.3)$ & $117,618(10.6)$ & $992,597(89.4)$ \\
\hline \multicolumn{7}{|l|}{ Age group in years } \\
\hline$<10$ & 283,541 & $488(0.2)$ & $283,053(99.8)$ & $287,422(13.0)$ & $495(0.2)$ & $286,927(99.8)$ \\
\hline $10-19$ & 234,837 & $521(0.2)$ & $234,316(99.8)$ & $236,884(10.7)$ & $606(0.3)$ & $236,278(99.7)$ \\
\hline $20-29$ & 305,611 & $1,892(0.6)$ & $303,719(99.4)$ & $311,773(14.1)$ & $2,257(0.7)$ & $309,516(99.3)$ \\
\hline $30-39$ & 327,012 & $4,715(1.4)$ & $322,297(98.6)$ & $330,199(15.0)$ & $5,343(1.6)$ & $324,856(98.4)$ \\
\hline $40-49$ & 319,407 & $4,371(1.4)$ & $315,036(98.6)$ & $323,168(14.6)$ & $5,116(1.6)$ & $318,052(98.4)$ \\
\hline $50-59$ & 254,154 & $7,906(3.1)$ & $246,248(96.9)$ & 263,216 (11.9) & $9,094(3.5)$ & $254,122(96.5)$ \\
\hline $60-69$ & 224,687 & $54,003(24.0)$ & $170,684(76.0)$ & $222,631(10.1)$ & $52,957(23.8)$ & $169,674(76.2)$ \\
\hline $70-79$ & 136,323 & $76,112(55.8)$ & $60,211(44.2)$ & $146,285(6.6)$ & $79,824(54.6)$ & $66,461(45.4)$ \\
\hline$\geq 80$ & 85,635 & $49,699(58.0)$ & $35,936(42.0)$ & $85,594(3.9)$ & $50,017(58.4)$ & $35,577(41.6)$ \\
\hline \multicolumn{7}{|l|}{ Mosaic income/education } \\
\hline Highest income and education & 990,078 & $93,330(9.4)$ & $869,748(90.6)$ & $1,001,695$ & $97,153(9.7)$ & $904,542(90.3)$ \\
\hline Middle income and education & 381,870 & $36,128(9.5)$ & $345,742(90.5)$ & 389,999 & $37,076(9.5)$ & $352,923(90.5)$ \\
\hline Lowest income and education & 776,802 & $69,729(9.0)$ & $707,073(91.0)$ & 786,842 & $70,113(8.8)$ & $716,729(91.2)$ \\
\hline Missing & 22,457 & $890(4.0)$ & $21,567(96.0)$ & 28,636 & $1,367(4.8)$ & $27,269(95.2)$ \\
\hline \multicolumn{7}{|l|}{ Comorbidity } \\
\hline Yes & 635,947 & $147,899(23.3)$ & $488,048(76.7)$ & $653,248(29.6)$ & $15,187(23.2)$ & $501,421(76.8)$ \\
\hline No & $1,535,260$ & $51,808(3.4)$ & $1,483,452(96.6)$ & $1,553,924(70.4)$ & $53,882(3.5)$ & $1,500,042(96.5)$ \\
\hline \multicolumn{7}{|l|}{ Previous seasonal vaccination ${ }^{b}$} \\
\hline Yes & 179,658 & $149,881(83.4)$ & $29,777(16.6)$ & $193,432(8.8)$ & $153,515(79.4)$ & $39,917(20.6)$ \\
\hline No & $1,991,549$ & $49,826(2.5)$ & $1,941,723(97.5)$ & $2,013,740(91.2)$ & $52,194(2.6)$ & $1,961,546(97.4)$ \\
\hline \multicolumn{7}{|l|}{ Pneumococcal vaccination ${ }^{c}$} \\
\hline Yes & 48,009 & $38,801(80.8)$ & $9,208(19.2)$ & $55,929(2.5)$ & $43,833(78.4)$ & $12,096(21.6)$ \\
\hline No & $2,123,198$ & $160,906(7.6)$ & $1,962,292(92.4)$ & $2,151,243(97.5)$ & $161,876(7.5)$ & $1,989,367(92.5)$ \\
\hline \multicolumn{7}{|l|}{ Pandemrix vaccination $^{d}$} \\
\hline Yes & 995,193 & $156,389(15.7)$ & $838,804(84.3)$ & $981,065(44.5)$ & $157,771(16.1)$ & $823,294(83.9)$ \\
\hline No & $1,176,014$ & $43,382(3.7)$ & $1,132,632(96.3)$ & $1226107(55.5)$ & $47,938(3.9)$ & $1,178,169(96.1)$ \\
\hline
\end{tabular}

Influenza season defined as 1 October to 31 May in the following year.

a During 2013/14 and 2014/15, 99.4\% of seasonal influenza vaccination were carried out using Fluarix.

${ }^{b}$ Vaccinated against seasonal influenza during the previous season.

"Vaccinated against Streptococcus pneumoniae during time period from 2009 to the current season under investigation.

d Vaccinated against influenza $\mathrm{A}\left(\mathrm{H}_{1} \mathrm{~N}_{1}\right)$ during the 2009 pandemic.

closed cohort for each season. We used the Stockholm Mosaic system as a proxy for living conditions and socioeconomic status [9]. The Mosaic system is based on eleven mutually exclusive categories (e.g. living in a low-income urban apartment block, multicultural suburb, affluent inner city, countryside, etc.) and involves 120 smaller urban agglomerations. Data on vaccine exposures were retrieved from the vaccination register, Vaccinera, which contains all data on seasonal influenza, pandemic influenza and pneumococcal vaccination of persons belonging to medical risk groups from the region, since 2009. Regional coverage in this database is assumed to be $100 \%$ as high-risk persons are vaccinated free of charge within the programme and registration is mandatory and required for reimbursements to the healthcare provider. Data on influenza status and comorbidities were obtained from the inpatient, hospital outpatient, and primary care databases.

\section{Case definition}

Cases were defined as a clinical diagnosis of influenza during the season. International Classification of Diseases, 1oth revision (ICD-10) codes Jo9 (influenza due to certain identified influenza viruses), J10 (influenza due to other identified influenza virus) and J11 (influenza due to unidentified influenza virus with pneumonia) were used to identify influenza diagnoses from inpatient, hospital outpatient, and primary care 
registers in VAL [10]. In a recent study VAL had over 99\% coverage for inpatient care, 90\% coverage for hospital outpatient care, and estimated $85 \%$ coverage for primary care [8]. National-level reporting estimates a validity of $85-95 \%$ for inpatient care, depending on the ICD-10 diagnosis [11]. Influenza cases were classified as inpatient cases if they came from the inpatient register and as outpatient cases if they came from the hospital outpatient or primary care registers. The inpatient register defined the case if an individual existed in multiple registers.

For the purpose of subanalysis, inpatient or outpatient non-influenza pneumonia, using ICD-10 codes J12-J18, was allowed.

Comorbidities were extracted from VAL using ICD10 codes registered for a period of up to three years before the start of the respective season. ICD-10 codes for tumours (Coo-D48), diabetes (E10-14) and circulatory (loo-199) and non-acute respiratory illness (J40J99) were extracted.

\section{Vaccination status}

Vaccination dates and seasonal vaccine type were derived from Vaccinera. Three different trivalent inactivated vaccines, Vaxigrip (Sanofi Pasteur MSD, Lyon, France), Fluarix (GSK, Brentford, United Kingdom), and Inflexal V (Crucell, Janssen Vaccines, Leiden, The Netherlands), were used during the seasons covered. No high-dose or adjuvanted vaccines were available in Sweden during the four seasons. Individuals with influenza infection before vaccination, or up to 13 days post-vaccination, were considered to be unvaccinated as were those who did not receive the seasonal vaccine. Those with influenza infection $\geq 14$ days post vaccination were considered to be vaccinated. Pandemic influenza (Pandemrix, GSK) vaccination status from 2009/10 was included as a covariate as was pneumococcal vaccination (in the current season or previous seasons since 2009). Vaccination against seasonal influenza in the previous season was also included as a covariate.

\section{Influenza epidemiology}

According to the Public Health Agency of Sweden, when compared with previous seasons, influenza activity was high during the most recent of the four seasons (2014/15), moderate during the 2011/12 and 2012/13 seasons, and low during the 2013/14 season [12] (Figure). Influenza $A\left(\mathrm{H}_{3} \mathrm{~N}_{2}\right)$ dominated in the 2011/12 and 2014/15 seasons, influenza $\mathrm{A}\left(\mathrm{H}_{1} \mathrm{~N}_{1}\right)$ pdmog dominated in 2013/14, whereas both these and influenza $B$ viruses circulated in the $2012 / 13$ season. There was also a significant amount of influenza B cases (approximately one-third of the cases) in 2014/15. In all four seasons influenza peaked during the second half of February.

\section{Statistical analyses}

Hazard rate ratios (HRR) comparing influenza inpatient and outpatient incidence among vaccinated and unvaccinated individuals were calculated using Cox regression analyses. Models were adjusted for age (grouped into 10-year intervals), sex, comorbidity status, socioeconomic status, pandemic vaccination, previous season influenza vaccination and pneumococcal vaccination. Stratified analysis of elderly people, aged 65 years or older, and individuals with underlying chronic illnesses was also performed, including age as a linear variable. Vaccination status was included as a time-varying exposure in the model, so individuals could contribute both vaccinated and unvaccinated risk time. In the final model comorbidity was adjusted for as a dichotomous variable as yes or no. The overall seasonal influenza vaccine effectiveness (VE) was calculated as $(1-H R R) \times 100 \%$. Both HRR and VE were reported with $95 \%$ confidence intervals $(\mathrm{Cl})$.

Additional regression analyses modelled VE on inpatient and outpatient pneumonia (ICD-10 J12-J18), adjusting for age (grouped into 10-year intervals), sex, comorbidity status, pandemic vaccination, previous season influenza vaccination and pneumococcal vaccination.

Regression analyses for the pre-influenza periods, 1 June to 30 September of the four seasons under investigation were performed to assess whether there was a healthy-vaccinee bias present in the cohort. Previous studies have reported on such a bias, which would augment VE estimates [13,14]. Pre-season analyses modelling influenza among those vaccinated later during the season were adjusted for age, sex and comorbidity status.

Data management and analyses were carried out using SAS Enterprise software (SAS Institute Inc., Cary, NC).

\section{Ethical consideration}

This analysis was part of ongoing programme evaluations required at the Department of Communicable Disease Control and Prevention, Stockholm County Council, Stockholm, Sweden. As this evaluation was a requisite part of Stockholm County Council work processes, it falls outside the mandate for the Regional Ethics committee. PINs have been anonymised in VAL and no data making individual identification possible is retained.

\section{Results}

In total, 2-2.2 million individuals were included per season in the study (Tables $1 \mathrm{~A}$ and $1 \mathrm{~B}$ ). A slightly higher proportion of women were vaccinated compared to men. (Tables $1 \mathrm{~A}$ and $1 \mathrm{~B}$ ). The number of patients with a clinical diagnosis of influenza was highest in 2011/12 and in 2014/15, seasons dominated by influenza $\mathrm{A}\left(\mathrm{H}_{3} \mathrm{~N}_{2}\right)$, but the need for hospital treatment was about three times higher in 2014/15 than in 2011/12 (Table 2). The number of people hospitalised with a 
TABLE 2

Hazard ratios with 95\% confidence intervals and vaccine effectiveness estimates for seasonal influenza vaccination on influenza outcome including inpatient and outpatient cases, Stockholm County, influenza seasons 2011/12-2014/15

\begin{tabular}{|c|c|c|c|c|c|c|c|c|c|c|}
\hline \multirow{2}{*}{ Category } & \multirow{2}{*}{$\begin{array}{c}\text { Total } \\
\text { number }\end{array}$} & \multicolumn{3}{|c|}{ All cases } & \multicolumn{3}{|c|}{ Outpatient } & \multicolumn{3}{|c|}{ Inpatient } \\
\hline & & Cases & $\mathrm{HR}(95 \% \mathrm{Cl})$ & VE & Cases & $\mathrm{HR}(95 \% \mathrm{Cl})$ & VE & Cases & $\mathrm{HR}(95 \% \mathrm{Cl})$ & VE \\
\hline \multicolumn{11}{|l|}{$2011 / 12$} \\
\hline \multicolumn{11}{|l|}{ All } \\
\hline Unvaccinated & $1,883,612$ & 5,109 & Ref & NA & 4,793 & Ref & NA & 316 & Ref & NA \\
\hline Vaccinated & 205,415 & 374 & $\begin{array}{l}0.81(0.69- \\
0.94)\end{array}$ & $19 \%(6-31)$ & 210 & $\begin{array}{c}0.69(0.57- \\
0.84) \\
\end{array}$ & $\begin{array}{c}31 \%\left(14^{-}\right. \\
43)\end{array}$ & 164 & $\begin{array}{c}1.07(0.79- \\
1.46)\end{array}$ & 0 \\
\hline \multicolumn{11}{|l|}{ Age $\geq 65$ years } \\
\hline Unvaccinated & 140,143 & 263 & Ref & NA & 161 & Ref & NA & 102 & Ref & NA \\
\hline Vaccinated & 176,622 & 299 & $\begin{array}{c}0.90(0.72- \\
1.12)\end{array}$ & $10 \%(0-28)$ & 149 & $\begin{array}{c}0.86 \\
(0.64-1.17)\end{array}$ & $\begin{array}{c}14 \% \\
(0-36)\end{array}$ & 150 & $\begin{array}{c}0.94 \\
(0.68-1.31)\end{array}$ & $6 \%(0-32)$ \\
\hline \multicolumn{11}{|l|}{$2012 / 13$} \\
\hline \multicolumn{11}{|l|}{ All } \\
\hline Unvaccinated & $1,935,823$ & 2,471 & Ref & NA & 1,885 & Ref & NA & 586 & Ref & NA \\
\hline Vaccinated & 185,646 & 139 & $\begin{array}{c}0.60(0.48- \\
0.77) \\
\end{array}$ & $40 \%(23-52)$ & 48 & $\begin{array}{c}0.55 \\
(0.37-0.81)\end{array}$ & $\begin{array}{c}45 \% \\
(19-63) \\
\end{array}$ & 91 & $\begin{array}{c}0.53(0.39- \\
0.73)\end{array}$ & $\begin{array}{c}47 \% \\
(27-61) \\
\end{array}$ \\
\hline \multicolumn{11}{|l|}{ Age $\geq 65$ years } \\
\hline Unvaccinated & 163,988 & 202 & Ref & NA & 55 & Ref & NA & 147 & Ref & NA \\
\hline Vaccinated & 162,678 & 106 & $\begin{array}{c}0.51(0.38- \\
0.69)\end{array}$ & $49 \%(31-62)$ & 31 & $\begin{array}{c}0.62 \\
(0.35-1.10)\end{array}$ & $\begin{array}{c}38 \% \\
(0-65) \\
\end{array}$ & 75 & $\begin{array}{c}0.48 \\
(0.34-0.69)\end{array}$ & $\begin{array}{c}52 \%(31- \\
66)\end{array}$ \\
\hline \multicolumn{11}{|l|}{$2013 / 14$} \\
\hline \multicolumn{11}{|l|}{ All } \\
\hline Unvaccinated & $1,971,500$ & 2,076 & Ref & NA & 1,850 & Ref & NA & 226 & Ref & NA \\
\hline Vaccinated & 199,707 & 105 & $\begin{array}{c}0.63(0.48- \\
0.83)\end{array}$ & $37 \%(17-52)$ & 57 & $\begin{array}{c}0.58 \\
(0.41-0.83) \\
\end{array}$ & $\begin{array}{c}42 \% \\
(17-59) \\
\end{array}$ & 48 & $\begin{array}{c}0.70 \\
(0.44-1.11) \\
\end{array}$ & $\begin{array}{c}30 \% \\
(0-56) \\
\end{array}$ \\
\hline \multicolumn{11}{|l|}{ Age $\geq 65$ years } \\
\hline Unvaccinated & 166,024 & 129 & Ref & NA & 58 & Ref & NA & 71 & Ref & NA \\
\hline Vaccinated & 170,752 & 74 & $\begin{array}{c}0.54\left(0.37^{-}\right. \\
0.79) \\
\end{array}$ & $46 \%(21-56)$ & 33 & $\begin{array}{c}0.59 \\
(0.33-1.05) \\
\end{array}$ & $\begin{array}{c}41 \% \\
(0-67) \\
\end{array}$ & 41 & $\begin{array}{c}0.51 \\
(0.31-0.83)\end{array}$ & $\begin{array}{c}49 \% \\
(17-69) \\
\end{array}$ \\
\hline \multicolumn{11}{|l|}{$2014 / 15$} \\
\hline \multicolumn{11}{|l|}{ All } \\
\hline Unvaccinated & $2,001,463$ & 4829 & Ref & NA & 3,980 & Ref & NA & 849 & Ref & NA \\
\hline Vaccinated & 205,709 & 829 & $\begin{array}{c}0.85(0.76- \\
0.95)\end{array}$ & $15 \%(5-24)$ & 298 & $\begin{array}{c}0.83 \\
(0.70-0.98) \\
\end{array}$ & $\begin{array}{c}17 \% \\
(2-30)\end{array}$ & 531 & $\begin{array}{c}0.84 \\
(0.72-0.99)\end{array}$ & $16 \%(1-28)$ \\
\hline \multicolumn{11}{|l|}{ Age $\geq 65$ years } \\
\hline Unvaccinated & 172,245 & 697 & Ref & NA & 212 & Ref & NA & 485 & Ref & NA \\
\hline Vaccinated & 173,075 & 705 & $\begin{array}{c}0.82(0.71- \\
0.93)\end{array}$ & $18 \%(7-29)$ & 204 & $\begin{array}{c}0.89 \\
(0.69-1.15)\end{array}$ & $11 \%(0-31)$ & 501 & $\begin{array}{c}0.79 \\
(0.68-0.93)\end{array}$ & $21 \%(7-32)$ \\
\hline
\end{tabular}

Cl: confidence interval; HR: hazard ratio; NA: not applicable; Ref: reference value; VE: vaccine effectiveness.

International Classification of Diseases, 10th revision codes J09-J11 were used to identify influenza diagnoses [10].

Vaccine effectiveness calculated $(1-\mathrm{HR} \times 100)$.

Hazard ratios derived from Cox proportional hazards regression model; adjusted for sex, age (age groups 10-year intervals), comorbidity status, socioeconomic status, previous seasonal vaccination, pneumococcal vaccination and Pandemrix vaccination. As complete case analysis was used, the number of cases decreased due to missing in socioeconomic status.

diagnosis of influenza during the influenza seasons followed the curve of laboratory-confirmed cases in the county (Figure).

In $2011 / 12$, more than $99 \%$ of all those vaccinated received Vaxigrip, while in the remaining seasons more than $99 \%$ were vaccinated with Flurarix. Almost 30\% of the individuals included in the analysis had a documented comorbidity and of these ca $25 \%$ were vaccinated. There were no differences in vaccination rates among those with high or low socioeconomic status (Tables $1 \mathrm{~A}$ and $1 \mathrm{~B}$ ).

For the 2011/12 season, overall VE for inpatient and outpatient care was $19 \%$ (95\% Cl: 6-31), driven primarily by outpatient effects in those younger than 65 years of age (Table 2). For the $2012 / 13$ season, overall VE was higher, 40\% (95\% Cl: 23-52), with stronger VE seen among inpatients, particularly those 65 years of age or older (VE: 52\%; 95\% Cl: 31-66). For the 2013/14 
Stratified analyses presenting hazard ratios with 95\% confidence intervals and vaccine effectiveness estimates for seasonal influenza vaccination on influenza outcome among individuals with comorbidity, Stockholm County, influenza seasons 2011/12-2014/15

\begin{tabular}{|c|c|c|c|c|c|c|c|c|c|c|}
\hline \multirow{2}{*}{ Category } & \multirow{2}{*}{$\begin{array}{c}\text { Total } \\
\text { number }\end{array}$} & \multicolumn{3}{|c|}{$\begin{array}{c}\text { All cases among those with } \\
\text { comorbidity }\end{array}$} & \multicolumn{3}{|c|}{$\begin{array}{l}\text { Outpatient among those with } \\
\text { comorbidity }\end{array}$} & \multicolumn{3}{|c|}{$\begin{array}{c}\text { Inpatient among those with } \\
\text { comorbidity }\end{array}$} \\
\hline & & Cases & $\operatorname{HR}(95 \% \mathrm{Cl})$ & VE & Cases & $\mathrm{HR}(95 \% \mathrm{Cl})$ & VE & Cases & $\mathrm{HR}(95 \% \mathrm{Cl})$ & VE \\
\hline \multicolumn{11}{|l|}{$2011 / 12$} \\
\hline \multicolumn{11}{|l|}{ All } \\
\hline Unvaccinated & 438,274 & 1,624 & Ref & NA & 1,424 & Ref & NA & 200 & Ref & NA \\
\hline Vaccinated & 148,196 & 307 & $\begin{array}{l}0.79(0.66- \\
0.95)\end{array}$ & $21 \%(5-34)$ & 164 & $\begin{array}{c}0.71\left(0.57^{-}\right. \\
0.90)\end{array}$ & $14 \%(0.36)$ & 143 & $\begin{array}{c}0.90\left(0.65^{-}\right. \\
1.24) \\
\end{array}$ & $10 \%(0-35)$ \\
\hline \multicolumn{11}{|l|}{ Age $\geq 65$ years } \\
\hline Unvaccinated & 8,205 & 193 & Ref & NA & 103 & Ref & NA & 90 & Ref & NA \\
\hline Vaccinated & 131,456 & 249 & $\begin{array}{l}0.85(0.66- \\
1.09)\end{array}$ & $15 \%(0-34)$ & 117 & $\begin{array}{c}0.87(0.61- \\
1.23)\end{array}$ & $13 \%(0-39)$ & 132 & $\begin{array}{c}0.83 \\
(0.60-1.18) \\
\end{array}$ & $17 \%(0-40)$ \\
\hline \multicolumn{11}{|l|}{$2012 / 13$} \\
\hline \multicolumn{11}{|l|}{ All } \\
\hline Unvaccinated & 475,163 & 949 & Ref & NA & 607 & Ref & NA & 342 & Ref & NA \\
\hline Vaccinated & 138,020 & 117 & $\begin{array}{l}0.54(0.41- \\
0.70)\end{array}$ & $46 \%(30-59)$ & 36 & $\begin{array}{c}0.56 \\
(0.35-0.89) \\
\end{array}$ & $\begin{array}{c}44 \% \\
(11-65)\end{array}$ & 81 & $\begin{array}{c}0.50 \\
(0.36-0.69) \\
\end{array}$ & $50 \%(31-64)$ \\
\hline \multicolumn{11}{|l|}{ Age $\geq 65$ years } \\
\hline Unvaccinated & 106,110 & 180 & Ref & NA & 47 & Ref & NA & 133 & Ref & NA \\
\hline Vaccinated & 123,472 & 94 & $\begin{array}{c}0.47 \\
(0.34-0.64)\end{array}$ & $53 \%(37-66)$ & 24 & $\begin{array}{c}0.51 \\
(0.27-0.95) \\
\end{array}$ & $49 \%(5-73)$ & 70 & $\begin{array}{c}0.47 \\
(0.33-0.67) \\
\end{array}$ & $53 \%(33-67)$ \\
\hline \multicolumn{11}{|l|}{$2013 / 14$} \\
\hline \multicolumn{11}{|l|}{ All } \\
\hline Unvaccinated & 488,048 & 745 & Ref & NA & 604 & Ref & NA & 141 & Ref & NA \\
\hline Vaccinated & 147,899 & 93 & $\begin{array}{c}0.70 \\
(0.51-0.95) \\
\end{array}$ & $30 \%(5-49)$ & 51 & $\begin{array}{c}0.81 \\
(0.54-1.21) \\
\end{array}$ & $19 \%(0-46)$ & 42 & $\begin{array}{c}0.52 \\
(0.32-0.84)\end{array}$ & $48 \%(16-68)$ \\
\hline \multicolumn{11}{|l|}{ Age $\geq 65$ years } \\
\hline Unvaccinated & 108,496 & 104 & Ref & Ref & 37 & Ref & Ref & 67 & Ref & Ref \\
\hline Vaccinated & 130,592 & 67 & $\begin{array}{c}0.55 \\
(0.37-0.82) \\
\end{array}$ & $45 \%(18-63)$ & 30 & $\begin{array}{c}0.78 \\
(0.41-1.48) \\
\end{array}$ & $22 \%(0-59)$ & 37 & $\begin{array}{c}0.45 \\
(0.27-0.75) \\
\end{array}$ & $55 \%(25-73)$ \\
\hline \multicolumn{11}{|l|}{$2014 / 15$} \\
\hline \multicolumn{11}{|l|}{ All } \\
\hline Unvaccinated & 501,421 & 2,002 & Ref & Ref & 1,391 & Ref & Ref & 611 & Ref & Ref \\
\hline Vaccinated & 151,827 & 731 & $\begin{array}{c}0.85 \\
(0.75-0.97)\end{array}$ & $15 \%(3-25)$ & 237 & $\begin{array}{c}0.84 \\
(0.68-1.03)\end{array}$ & $16 \%(0-32)$ & 494 & $\begin{array}{c}0.85 \\
(0.72-1.00)\end{array}$ & $15 \%(0-28)$ \\
\hline \multicolumn{11}{|l|}{ Age $\geq 65$ years } \\
\hline Unvaccinated & 113,444 & 591 & Ref & NA & 164 & Ref & NA & 427 & Ref & NA \\
\hline Vaccinated & 133,226 & 639 & $\begin{array}{l}0.82(0.71- \\
0.94)\end{array}$ & $18 \%(6-29)$ & 169 & $\begin{array}{c}0.84(0.63- \\
1.11)\end{array}$ & $16 \%(0-37)$ & 470 & $\begin{array}{c}0.82(0.69- \\
0.97)\end{array}$ & $18 \%(3-31)$ \\
\hline
\end{tabular}

$\mathrm{CI}$ : confidence interval; HR: hazard ratios; NA: not applicable; Ref: reference value; VE: vaccine effectiveness

International Classification of Diseases, 10th revision codes J09-J11 were used to identify influenza diagnoses. [10]

${ }^{a}$ Vaccine effectiveness, calculated (1-HR $\left.\times 100\right)$.

${ }^{\mathrm{b}}$ Hazard ratios derived from Cox proportional hazards regression model; adjusted for sex, age (age groups 10 years intervals), socioeconomic status, previous seasonal vaccination, pneumococcal vaccination and Pandemrix vaccination. As complete case analysis was used, the number of cases decreased due to missing in socioeconomic status.

season, overall VE was 37\% (95\% Cl: 17-52), with elderly inpatient care driving the effects (VE: 49\%; 95\% Cl: $17-69$ for those 65 years or older). In 2014/15, the study season with the highest burden of hospital treatment of influenza, the VE was again lower and the vaccine effect was strongest for those 65 years, or older, 18\% (95 Cl: 7-29) overall and 21\% (95\% Cl: 7-32) for inpatient care.
For the two seasons with moderately high VEs, inpatient VE for patients with comorbidities was similar to that of the whole population (Table 3). Stratified analyses on comorbidity showed $48-55 \%$ effectiveness against inpatient care in the seasons 2012/13 and $2013 / 14$ for those with underlying chronic illness, both overall and among those 65 years of age or older. VE in outpatient care was not as strongly affected by comorbidity status. 
Stratified analyses on previous season influenza vaccination among those 65 years of age or older, showed no clear effects, either protective or negative, against the risk of being hospitalised with a diagnosis of influenza in the current season (data not shown).

The pre-influenza season analyses, 1 June to 30 September, were all statistically insignificant, with HRs of 1.71 (95\% Cl: $0.80-3.66$ ), 0.87 (95\% Cl: 0.29-2.56), 1.09 (95\% Cl: $0.45-2.65)$, and 0.83 (95\% Cl: $0.34^{-}$ 2.01 ), respectively, indicating that vaccination was not associated with either a decreased or increased risk of receiving a diagnosis of influenza in any of these four pre-influenza season periods.

VE for inpatient non-influenza pneumonia in persons aged 65 years or older ranged from $11 \%$ to $18 \%$ during the four seasons. No effectiveness could be demonstrated against non-hospitalised pneumonia (Table 4).

\section{Discussion}

In this study we used influenza and pneumonia diagnosis codes linked with vaccination status from the entire population of a large metropolitan area to evaluate seasonal influenza vaccine effectiveness on inpatient hospitalisations and primary care visits. Our results thus provide important real-world vaccination programme effects in individuals of varying ages and health statuses. Vaccine effects were moderately good both in adults 165 years of age and in elderly people ( $\geq 65$ years of age), including those with comorbidities, during two of the four seasons. Small but significant VE against non-influenza pneumonias was found in persons 65 years or older in all four seasons. However, since the proportion of pneumonia caused by influenza in most studies is less than $20 \%$, a VE of $11-18 \%$ for pneumonia hospitalisation in persons aged 65 years or older, of whom about half were vaccinated, could indicate a VE for influenza-related pneumonia as high as $50-75 \%[3]$.

Seasonal influenza programme vaccination is typically recommended to prevent severe outcomes in highly vulnerable groups. What constitutes optimal outcome measures for seasonal influenza VE is debatable, however. Commonly used outcome measures are influenzalike-illness (ILI), acute respiratory infection (ARI), or hospitalisation for influenza or pneumonia $[6,15,16]$. Effectiveness against laboratory-confirmed influenza vaccine type is the most specific outcome measure, although often available for relatively limited populations, such as healthy adults, and as such not fully generalisable to populations targeted for influenza programmes [2,4].

The four pre-influenza season period analyses did not show any difference in the risk of receiving a clinical diagnosis of influenza in vaccinated vs non-vaccinated persons, indicating that there was no healthy-vaccinee bias in the current study. This is in contrast to most studies, including an earlier study from Stockholm
$[13,14,17,18]$. The former Stockholm study was performed in 1998-2001 when the yearly seasonal influenza vaccination campaigns were new and included only adults aged 65 years or older. Vaccines were not offered free of charge as they are today, which may also explain the healthy-vaccinee bias found in that study [14]. In addition, during the last few years, Stockholm's influenza vaccine campaign has been developed specifically to target the chronically ill, irrespective of age.

Randomised control trials (RCTs) measuring influenza VE among elderly people are rare and the only one of high quality showed a $50 \%$ effect against serologically confirmed influenza [19]. Pooled observational studies have shown nominal effects among the elderly in nursing homes (ILI VE 23\%; hospitalisation for pneumonia VE $45 \%$ ), but non-significant effects on elderly people living in the community in terms of ILI or influenza [6]. Overall, observational VE estimates range from $25 \%$ to $60 \%$ in protecting against hospitalisation for influenza or pneumonia among the elderly $[6,16,20]$. Observational studies are often not able to account for specific effects among the chronically ill, which is a major limitation [16]. When treatment choice, or in this case vaccination status, is driven by an individual's disease status, it is referred to as confounding by indication and is another type of selection bias. The influenza vaccination programme promotes this population selection bias by targeting those with underlying comorbidities. A major strength in our study is that these effect results have accounted for this major bias by linking with patient records and adjusting for comorbidity status. Other strengths were that we adjusted for potential differences stemming from socioeconomic status and controlled for residual effects in seasonal VE estimates due to previous seasonal vaccinations [21,22], pandemic influenza and pneumococcal vaccinations.

The European network Influenza - Monitoring Vaccine Effectiveness (I-MOVE) has monitored VE in a number of countries since 2008 by observational studies using the 'test-negative' or 'screening' designs [1]. Our results among persons with comorbidity showing a very low VE in 2011/12, but a moderately good VE around $50 \%$ for prevention of hospitalisation for influenza among persons aged 65 years or older in 2012/13 and $2013 / 14$, are in accordance with those presented by I-MOVE. They found a very low VE during the 2011/12 season, from $43 \%$ during the early part of the season down to less than $10 \%$ in risk groups when the whole season was analysed $[23,24]$. The reason for this low VE late in the 2011/12 season may have been a waning vaccine effect in older persons, since the peak came late in the season, or an antigenic drift [24]. During the 2012/13 season, when all three influenza types circulated, I-MOVE reported a moderately high VE in Europe (43-63\% depending on influenza type), and also in $2013 / 14$ with a VE for the dominating influenza $\mathrm{A}\left(\mathrm{H}_{1} \mathrm{~N}_{1}\right)$ pdmog of $48 \%[23,25]$. Reports from the $2014 / 15$ season from North America and Europe are in accordance 
TABLE 4

Hazard ratios with 95\% confidence intervals and vaccine effectiveness estimates for seasonal influenza vaccination on pneumonia outcome including inpatient and outpatient cases, Stockholm County, influenza seasons 2011/12-2014/15

\begin{tabular}{|c|c|c|c|c|c|c|c|c|c|c|}
\hline \multirow{2}{*}{ Category } & \multirow{2}{*}{$\begin{array}{c}\text { Total } \\
\text { number }\end{array}$} & \multicolumn{3}{|c|}{ All cases } & \multicolumn{3}{|c|}{ Outpatient } & \multicolumn{3}{|c|}{ Inpatient } \\
\hline & & Cases & $\mathrm{HR}^{\mathrm{a}}(95 \% \mathrm{Cl})$ & $\mathrm{VE}^{\mathrm{b}}$ & Cases & $\mathrm{HR}^{\mathrm{a}}(95 \% \mathrm{Cl})$ & $\mathrm{VE}^{\mathrm{b}}$ & Cases & $\mathrm{HR}^{\mathrm{a}}(95 \% \mathrm{Cl})$ & $\mathrm{VE}^{\mathrm{b}}$ \\
\hline \multicolumn{11}{|l|}{$2011 / 12$} \\
\hline \multicolumn{11}{|l|}{ All } \\
\hline Unvaccinated & $1,884,818$ & 20,088 & Ref & NA & 15,123 & Ref & NA & 4,965 & Ref & NA \\
\hline Vaccinated & 204,229 & 4,849 & $1.15(1.09-1.20)$ & 0 & 2,267 & $1.28(1.20-1.37)$ & 0 & 2,582 & $\begin{array}{c}0.97(0.90- \\
1.07)\end{array}$ & $3 \%(0-10)$ \\
\hline \multicolumn{11}{|l|}{ Age $\geq 65$ years } \\
\hline Unvaccinated & 141,097 & 4,735 & Ref & NA & 1,878 & Ref & NA & 2,857 & Ref & NA \\
\hline Vaccinated & 175,668 & 4,333 & $\begin{array}{c}0.93 \\
(0.88-0.99)\end{array}$ & $7 \%(1-12)$ & 1,946 & $\begin{array}{c}1.14\left(1.04^{-}\right. \\
1.24)\end{array}$ & 0 & 2,387 & $\begin{array}{c}0.82(0.76- \\
0.88)\end{array}$ & $\begin{array}{c}18 \%(12- \\
24)\end{array}$ \\
\hline \multicolumn{11}{|l|}{$2012 / 13$} \\
\hline \multicolumn{11}{|l|}{ All } \\
\hline Unvaccinated & $1,936,790$ & 10,224 & Ref & NA & 8,013 & Ref & NA & 2,211 & Ref & NA \\
\hline Vaccinated & 184,679 & 3,606 & $\begin{array}{c}1.02 \\
(0.96-1.07)\end{array}$ & 0 & 1,518 & $\begin{array}{c}1.05 \\
(0.97-1.13) \\
\end{array}$ & 0 & 2,088 & $\begin{array}{c}0.97 \\
(0.90-1.04)\end{array}$ & $3 \%(0-10)$ \\
\hline \multicolumn{11}{|l|}{ Age $\geq 65$ years } \\
\hline Unvaccinated & 164,807 & 4,697 & Ref & NA & 1,787 & Ref & NA & 2,910 & Ref & NA \\
\hline Vaccinated & 161,859 & 3,250 & $\begin{array}{c}0.95 \\
(0.89-1.00) \\
\end{array}$ & $5 \%(0-11)$ & 1,319 & $\begin{array}{c}1.05 \\
(0.96-1.16) \\
\end{array}$ & 0 & 1,931 & $\begin{array}{c}0.89 \\
(0.83-0.96) \\
\end{array}$ & $11 \%(4-17)$ \\
\hline \multicolumn{11}{|l|}{$2013 / 14$} \\
\hline \multicolumn{11}{|l|}{ All } \\
\hline Unvaccinated & $1,972,363$ & 12,718 & Ref & NA & 8,527 & Ref & NA & 4,191 & Ref & NA \\
\hline Vaccinated & 198,844 & 3,737 & $\begin{array}{c}1.05 \\
(1.00-1.11) \\
\end{array}$ & 0 & 1,700 & $\begin{array}{c}1.20 \\
(1.11-1.29) \\
\end{array}$ & o & 2,037 & $\begin{array}{c}0.95 \\
(0.88-1.03)\end{array}$ & $5 \%(0-12)$ \\
\hline \multicolumn{11}{|l|}{ Age $\geq 65$ years } \\
\hline Unvaccinated & 166,773 & 4,247 & Ref & NA & 1,633 & Ref & NA & 2,614 & Ref & NA \\
\hline Vaccinated & 170,003 & 3,349 & $\begin{array}{c}1.00 \\
(0.94-1.06) \\
\end{array}$ & o & 1,455 & $\begin{array}{c}1.20 \\
(1.09-1.32) \\
\end{array}$ & o & 1,894 & $\begin{array}{c}0.89 \\
(0.82-0.96) \\
\end{array}$ & $11 \%(4-18)$ \\
\hline \multicolumn{11}{|l|}{$2014 / 15$} \\
\hline \multicolumn{11}{|l|}{ All } \\
\hline Unvaccinated & $2,002,587$ & 16,155 & Ref & NA & 11,336 & Ref & NA & 4,819 & Ref & NA \\
\hline Vaccinated & 204585 & 4636 & $\begin{array}{c}1.08 \\
(1.03-1.13) \\
\end{array}$ & 0 & 2,207 & $\begin{array}{c}1.17 \\
(1.09-1.25) \\
\end{array}$ & 0 & 2,429 & $\begin{array}{c}0.97 \\
(0.91-1.04) \\
\end{array}$ & $3 \%(0-9)$ \\
\hline \multicolumn{11}{|l|}{ Age $\geq 65$ years } \\
\hline Unvaccinated & 166773 & 5264 & Ref & NA & 2,221 & Ref & NA & 3,043 & Ref & NA \\
\hline Vaccinated & 173170 & 4146 & $\begin{array}{c}0.98\left(0.93^{-}\right. \\
1.03)\end{array}$ & $2 \%(0-7)$ & 1,905 & $1.12(1.03-1.22)$ & 0 & 2,241 & $\begin{array}{c}0.89 \\
(0.82-0.95)\end{array}$ & $11 \%(5-18)$ \\
\hline
\end{tabular}

$\mathrm{Cl}$ : confidence interval; HR: hazard ratio; NA: not applicable; Ref: reference value; VE: vaccine effectiveness.

International Classification of Diseases, 10th revision codes J12-J18 were used to identify non-influenza pneumonia diagnoses [10].

${ }^{a}$ Hazard ratios derived from Cox proportional hazards regression model; confidence interval; adjusted for sex, age (age groups 10 years

intervals), comorbidity status, socioeconomic status, previous seasonal vaccination, pneumococcal vaccination and Pandemrix vaccination.

As complete case analysis was used, the number of cases decreased due to missing in socioeconomic status.

${ }^{b}$ Vaccine effectiveness calculated $(1-H R \times 100)$.

with our findings that VE was lower than during the two preceding seasons [26-28]. A possible reason for this lower VE is that circulation of newly emerged $A\left(\mathrm{H}_{3} \mathrm{~N}_{2}\right)$ clades 3 C.3a and 3 C.2a viruses, to which antibodies in humans to the A/Texas/50/2012 antigens contained in the seasonal vaccine, reacted less well $[28,29]$.

Effects among adults under 65 years of age, particularly healthy individuals, should theoretically be higher than in elderly people, as they have a better immune response to vaccination. In contrast, VE among healthy adults below 65 years in our study was similar to, or lower than among the elderly. A possible reason for this finding is a potential misclassification of exposure, since entering influenza vaccination of healthy adults below 65 years in the vaccination register is not requisite, as Stockholm neither recommends nor subsidises influenza vaccinations for these individuals. If healthy individuals aged under 65 years obtain vaccinations via mobile clinics at their workplace or via a healthcare provider, they may not be entered in the vaccination register. As such, some may be inappropriately 
classified as unvaccinated in our study, and hence weaken the effect measures of VE. In contrast, persons belonging to risk groups according to the programme will most likely have been registered in the vaccination register, since they are offered the vaccine free of charge and have easy access to caregivers included in the programme. In addition, caregivers are reimbursed only when they adhere to the reporting requirements.

Although we did not see any evidence of a healthyvaccinee bias in pre-season analyses, the power of this analysis was low since the few cases with influenza diagnoses off-season resulted in wide confidence intervals. Another limitation is that VAL experienced a technical problem while merging primary care data for $\mathbf{2 0 1 3}$, and thus it appears as if there are a reduced number of primary care cases for this year. This technical problem is non-differential and, if anything, would generate diluted VEs. Inpatient care is complete and not affected by these technicalities. We could not control for the severity of comorbidity or the severity of the acute disease in order to identify patients in need of intensive care treatment, nor could we analyse mortality outcomes, since these data are not included in the County's surveillance. Negative controls were not included in these analyses, although pneumonia was included as a subanalysis, and while significant VE was found, it was very low because of the diluting effect of such a non-specific diagnosis.

Our study found robust VE against influenza hospitalisation, a proxy for severe disease. This VE was most substantial among adults and the elderly having underlying chronic conditions. Therefore, we believe that public health officials should focus resources also on attaining high coverage in people with underlying diseases, irrespective of age, in addition to the WHO/EU goal of a $75 \%$ for coverage among all people 65 years of age or older [30].

The need for additional effectiveness studies for the influenza vaccine with non-specific outcomes such as pneumonia or influenza-like illness has been questioned since the potential for overestimation or underestimation of vaccine effectiveness is too great [3]. Although the influenza diagnoses were not laboratoryconfirmed, our study demonstrates that comprehensive population-based patient register data on influenzaspecific outcomes, which allow for adjustments of multiple confounders and assessments of potential biases, can and should be used for routine estimates of seasonal influenza IVE and VE. The VEs in our study were in accordance with those from European multicentre studies using the much more laborious test-negative design [25,31,32]. International sentinel surveillance efforts remain vital to gauge circulating types, but are not needed to accurately assess VE across broad populations. In addition, large and expensive RCTs to estimate effects of seasonal influenza vaccines are neither fiscally nor ethically justifiable in the era of reliable electronic medical record data.
Since the beginning of 2016 we have had a regular weekly linkage between Stockholm's central database for healthcare diagnoses, VAL, and the vaccine register [33]. These real-time data showed that the 55-68\% IVE seen in persons aged 65 years or older during January and February, when $\mathrm{A}\left(\mathrm{H}_{1} \mathrm{~N}_{1}\right)$ pdmog dominated, declined when influenza B (Victoria) took over and was only $43-44 \%$ from the end of March, an observation which lead us to take action and recommend that doctors prescribe early antiviral therapy for ILI in this patient group.

In conclusion, results from this population-based evaluation of multiple vaccine seasons show substantial protective VE against being hospitalised with a diagnosis of influenza among elderly and chronically ill persons in all age groups during two of four seasons and lower, but still significant, VE in another. Programmes that target these vulnerable populations can anticipate ca $50 \%$ reductions in influenza-specific inpatient care, in seasons with a good antigenic match. We also demonstrate that the use of population-based patient register data on influenza-specific outcomes enables valuable real-time estimates of seasonal influenza vaccine effectiveness.

\section{Acknowledgements}

The authors would like to thank Göran Lord for VAL database support, development and insights. We would also like to acknowledge our dedicated colleagues within SLL and Smittskydd Stockholm for all vaccination programme achievements.

\section{Conflict of interest}

None declared. Dr Amy Leval became an employee at Janssen-Cilag after the study was designed, initial analyses performed and manuscript drafted. This study was not sponsored by Janssen-Cilag nor does it represent the opinions thereof.

\section{Authors' contributions}

All authors participated in the planning, analysis and writing of the manuscript of this study. M-PH had full access to all the data in the study and takes responsibility for the integrity of the data. $\mathrm{M}-\mathrm{PH}$ and $\mathrm{AL}$ take responsibility for the accuracy of the data analyses.

\section{References}

1. Valenciano M, Ciancio B, I-MOVE study team. I-MOVE: a European network to measure the effectiveness of influenza vaccines. Euro Surveill. 2012;17(39):20281.PMID: 23041022

2. Valenciano M, Kissling E, Ciancio BC, Moren A. Study designs for timely estimation of influenza vaccine effectiveness using European sentinel practitioner networks.Vaccine. 2010;28(46):7381-8. DOI: 10.1016/j.vaccine.2010.09.010 PMID: 20851086

3. Belongia EA, Shay DK. Influenza vaccine for communityacquired pneumonia.Lancet. 2008;372(9636):352-4. DOI: 10.1016/S0140-6736(08)61137-X PMID: 18675671

4. Treanor JJ, Talbot HK, Ohmit SE, Coleman LA, Thompson MG, Cheng PY, et al. Effectiveness of seasonal influenza vaccines in the United States during a season with circulation of all 
three vaccine strains. Clin Infect Dis. 2012;55(7):951-9. DOI: 10.1093/cid/cis574 PMID: 22843783

5. Pebody RG, Mølbak K. Importance of timely monitoring of seasonal influenza vaccine effectiveness. Euro Surveill. 2016;21(16):30209. DOI: 10.2807/1560-7917. ES.2016.21.16.30209 PMID: 27123870

6. Jefferson T, Di Pietrantonj C, Al-Ansary LA, Ferroni E, Thorning $\mathrm{S}$, Thomas RE. Vaccines for preventing influenza in the elderly. Cochrane Database Syst Rev. 2010; (2):CDo04876.PMID: 20166072

7. Beyer WEP, McElhaney J, Smith DJ, Monto AS, Nguyen-VanTam JS, Osterhaus ADME. Cochrane re-arranged: support for policies to vaccinate elderly people against influenza.Vaccine. 2013;31(50):6030-3. DOI: 10.1016/j.vaccine.2013.09.063 PMID: 24095882

8. Carlsson AC, Wändell P, Ösby U, Zarrinkoub R, Wettermark $B$, Ljunggren $G$. High prevalence of diagnosis of diabetes, depression, anxiety, hypertension, asthma and COPD in the total population of Stockholm, Sweden - a challenge for public health.BMC Public Health. 2013;13(1):670. DOI: 10.1186/14712458-13-670 PMID: 23866784

9. JSzegö J. Bebyggelsens mosaik [The mosaic of the settlement]. Rapport 7:2009. Stockholm: Regionplanekontoret; 2009. Swedish. Available from: http://www.rufs.se/ publikationer/20092/20097-bebyggelsens-mosaik/http://

10. World Health Organization (WHO). International statistical classification of diseases and related health problems. 10th Revision. Volume 2. Instruction manual. 2010 ed. Geneva: WHO; 2011. Available from: http://www.who.int/ classifications/icd/ICD10Volume2_en_2010.pdf

11. Ludvigsson JF, Andersson E, Ekbom A, Feychting M, Kim JL, Reuterwall $C$, et al. External review and validation of the Swedish national inpatient register. BMC Public Health. 2011;11(1):450. DOI: 10.1186/1471-2458-11-450 PMID: 21658213

12. Public Health Agency of Sweden Influenza in Sweden 20142015 Season. [Accessed 5 Aug 2016] Available from: https:// www.folkhalsomyndigheten.se/pagefiles/21868/Influenza-inSweden-2014-2015.pdf

13. Jackson LA, Jackson ML, Nelson JC, Neuzil KM, Weiss NS. Evidence of bias in estimates of influenza vaccine effectiveness in seniors.Int J Epidemiol. 2006;35(2):337-44. DOI: 10.1093/ije/ dyi274 PMID: 16368725

14. Örtqvist A, Granath F, Askling J, Hedlund J. Influenza vaccination and mortality: prospective cohort study of the elderly in a large geographical area.Eur Respir J. 2007;30(3):414-22. DOI: 10.1183/09031936.00135306 PMID: 17537767

15. Jefferson TO, Rivetti D, Di Pietrantonj C, Rivetti A, Demicheli V. Vaccines for preventing influenza in healthy adults.Cochrane Database Syst Rev. 2007; (2):CDo01269.PMID: 17443504

16. Michiels B, Govaerts F, Remmen R, Vermeire E, Coenen S. A systematic review of the evidence on the effectiveness and risks of inactivated influenza vaccines in different target groups.Vaccine. 2011;29(49):9159-70. DOI: 10.1016/j. vaccine.2011.08.008 PMID: 21840359

17. Jackson ML, Yu O, Nelson JC, Naleway A, Belongia EA, Baxter $R$, et al. Further evidence for bias in observational studies of influenza vaccine effectiveness: the 2009 influenza $A\left(\mathrm{H}_{1} \mathrm{~N}_{1}\right)$ pandemic. Am J Epidemiol. 2013;178(8):1327-36. DOI: 10.1093/ aje/kwt124 PMID: 23978527

18. Remschmidt C, Wichmann O, Harder T. Frequency and impact of confounding by indication and healthy vaccinee bias in observational studies assessing influenza vaccine effectiveness: a systematic review.BMC Infect Dis. 2015;15(1):429. DOI: 10.1186/s12879-015-1154-y PMID: 26474974

19. Govaert TM, Thijs CT, Masurel N, Sprenger MJ, Dinant GJ, Knottnerus JA. The efficacy of influenza vaccination in elderly individuals. A randomized double-blind placebocontrolled trial.JAMA. 1994;272(21):1661-5. DOI: 10.1001/ jama.1994.03520210045030 PMID: 7966893

20. Darvishian M, Gefenaite G, Turner RM, Pechlivanoglou P, Van der Hoek W, Van den Heuvel ER, et al. After adjusting for bias in meta-analysis seasonal influenza vaccine remains effective in community-dwelling elderly. J Clin Epidemiol. 2014;67(7):734-44. DOI: 10.1016/j.jclinepi.2014.02.009 PMID: 24768004

21. McLean HQ, Thompson MG, Sundaram ME, Meece JK, McClure $\mathrm{DL}$, Friedrich TC, et al. Impact of repeated vaccination on vaccine effectiveness against influenza $A\left(\mathrm{H}_{3} \mathrm{~N}_{2}\right)$ and $B$ during 8 seasons. Clin Infect Dis. 2014;59(10):1375-85. DOI: 10.1093/cid/ ciu680 PMID: 25270645

22. Voordouw AC, Sturkenboom MC, Dieleman JP, Stijnen T, Smith DJ, van der Lei J, et al. Annual revaccination against influenza and mortality risk in community-dwelling elderly persons.
JAMA. 2004;292(17):2089-95. DOI: 10.1001/jama.292.17.2089 PMID: 15523069

23. Kissling E, Valenciano M, I-MOVE Case-Control Studies Team. Early estimates of seasonal influenza vaccine effectiveness in Europe among target groups for vaccination: results from the I-MOVE multicentre case-control study, 2011/12.Euro Surveill. 2012;17(15):20146.PMID: 22516046

24. Kissling E, Valenciano M, Larrauri A, Oroszi B, Cohen JM, Nunes $B$, et al. Low and decreasing vaccine effectiveness against influenza $A\left(\mathrm{H}_{3}\right)$ in $2011 / 12$ among vaccination target groups in Europe: results from the I-MOVE multicentre casecontrol study. Euro Surveill. 2013;18(5):20390.PMID: 23399425

25. Valenciano M, Kissling E, Reuss A, Jiménez-Jorge S, Horváth JK, Donnell JM, et al. The European I-MOVE Multicentre 2013-2014 Case-Control Study. Homogeneous moderate influenza vaccine effectiveness against $A\left(\mathrm{H}_{1} \mathrm{~N}_{1}\right)$ pdmog and heterogenous results by country against $A\left(\mathrm{H}_{3} \mathrm{~N}_{2}\right)$. Vaccine. 2015;33(24):2813-22. DOI: 10.1016/j.vaccine.2015.04.012 PMID: 25936723

26. Flannery B, Clippard J, Zimmerman RK, Nowalk MP, Jackson $M L$, Jackson LA, et al. Early estimates of seasonal influenza vaccine effectiveness - United States, January 2015. MMWR Morb Mortal Wkly Rep. 2015;64(1):10-5.PMID: 25590680

27. Pebody R, Warburton F, Andrews N, Ellis J, von Wissmann $B$, Robertson C, et al. Effectiveness of seasonal influenza vaccine in preventing laboratory-confirmed influenza in primary care in the United Kingdom: 2014/15 end of season results. Euro Surveill. 2015;20(36):30013. DOI: 10.2807/15607917.ES.2015.20.36.30013 PMID: 26535911

28. Skowronski DM, Chambers C, Sabaiduc S, De Serres G, Winter AL, Dickinson JA, et al. A Perfect Storm: Impact of Genomic Variation and Serial Vaccination on Low Influenza Vaccine Effectiveness During the 2014-2015 Season. Clin Infect Dis. 2016;63(1):21-32. DOI: 10.1093/cid/ciw176 PMID: 27025838

29. World Health Organisation (WHO). Recommended composition of influenza virus vaccines for use in the 2015 southern hemisphere influenza season. [Accessed 10 May 2016]. Available from: http://www.who.int/influenza/vaccines/virus/ recommendations/201409 recommendation.pdf

30. European Commission. Council Recommendation of 22 December 2009 on seasonal influenza vaccination (2009/1019/ EU) Official Journal of the European Union. Luxembourg: Publications Office of the European Union. 29.12.2009: 348/71. Available from: http://eur-lex.europa.eu/legal-content/ EN/ALL/?uri=CELEX:32009H1019

31. Kissling E, Valenciano M, Buchholz U, Larrauri A, Cohen JM, Nunes $B$, et al. Influenza vaccine effectiveness estimates in Europe in a season with three influenza type/subtypes circulating: the I-MOVE multicentre case-control study, influenza season 2012/13. Euro Surveill. 2014;19(6):20701. DOI: $10.2807 / 1560-7917 . E S 2014$ 19.6.20701 PMID: 24556348

32. Rondy M, Launay 0 , Puig-Barberà J, Gefenaite G, Castilla J, de Gaetano Donati K, et al. 2012/13 influenza vaccine effectiveness against hospitalised influenza $A\left(\mathrm{H}_{1} \mathrm{~N}_{1}\right)$ pdmog, $\mathrm{A}\left(\mathrm{H}_{3} \mathrm{~N}_{2}\right)$ and $\mathrm{B}$ : estimates from a European network of hospitals. Euro Surveill. 2015;20(2):21011. DOI: 10.2807/15607917.ES2015.20.2.21011 PMID: 25613779

33. Smittskydd Stockholm. Influensasäsongen 2015-2016 [Influenza season 2015-2016]. 27 June 2015. Available from: http://www.vardgivarguiden.se/behandlingsstod/smittskydd/ dokument/statistik/influensa/influensasasongen-2015-2016/

\section{License and copyright}

This is an open-access article distributed under the terms of the Creative Commons Attribution (CC BY 4.0) Licence. You may share and adapt the material, but must give appropriate credit to the source, provide a link to the licence, and indicate if changes were made.

This article is copyright of the authors, 2016. 